\title{
Brood parasitism on Meadow Pipits Anthus pratensis by Common Cuckoos Cuculus canorus in two mountain areas in Norway
}

\author{
Jan Berstad ${ }^{1 *}$, Bård G. Stokke² \& Arne Moksnes ${ }^{3}$ \\ ${ }^{1}$ Lilleruts vei 10, N-1364 Fornebu, Norway \\ ${ }^{2}$ Norwegian Institute for Nature Research, P. O. Box 5685 Torgarden, N-7485 Trondheim, Norway \\ ${ }^{3}$ Department of Biology, Norwegian University of Science and Technology, NTNU, N-7491, Trondheim, Norway \\ *Correspondence: jan.berstad@gmail.com
}

\begin{abstract}
In the period 2001-2014 we studied Common Cuckoo Cuculus canorus brood parasitism on Meadow Pipits Anthus pratensis in two mountain areas; one located in the eastern and one in the western part of southern Norway. In the total material of 211 Meadow Pipit nests, 14 (6.6\%) were parasitized by the cuckoo. The parasitism rate showed considerable variation both in time and space, with highest rate in one of the areas in 2005 (35.3\%). Cuckoo eggs were quite similar in appearance to host eggs. In spite of this, $30 \%$ of the cuckoo eggs were rejected by desertion. No host ejection of parasite eggs was observed. Nest predation rates were rather low. Due to climate change, it has been hypothesized that the cuckoo, a long-distance migrant, may arrive too late to successfully utilize the Meadow Pipit because the latter is better able to advance the breeding season due to a shorter migration distance. Our data lend support to the mismatch hypothesis, but the low sample size regarding cases of parasitism does not allow us to make any firm conclusions. Long-term monitoring of host-parasite interactions in specific populations is important to further disclose the mechanisms responsible for the decline in the Norwegian cuckoo population.
\end{abstract}

Keywords: Climate change, mismatch, brood parasitism, Common Cuckoo, Meadow Pipit

\section{INTRODUCTION}

The Meadow Pipit Anthus pratensis is by far the most common host for the Common Cuckoo Cuculus canorus (hereafter cuckoo) in Norway (Moksnes \& Røskaft 1987, Moksnes et al. 2011). In previous studies, a marked decrease in the Norwegian cuckoo population has been reported, with an annual reduction of approximately 4.2\% in the period 1996-2013 (Kålås et al. 2014, Moksnes 2014). Based on these estimates, the cuckoo was placed on the Norwegian Red List of Species as «Near Threatened» in 2015 (https://www. artsdatabanken.no/Rodliste). Similar negative trends have been recorded in several other European countries (Birdlife International 2004, Eaton et al. 2009, Erritzøe et al. 2012).

The mechanisms behind this decrease may operate both at the breeding grounds, during migration and/ or in the African winter quarters. Nearly all scientific studies on cuckoos have been carried out at the breeding grounds, and, unfortunately, there are no scientific data available on winter survival. In later years, however, satellite tracking has revealed that British cuckoos use two distinct autumn migration routes, of which mortality during migration was higher for birds using a western rather than an eastern route (Hewson et al. 2016). This result indicates that threats during migration are operating.
Even if the decrease in cuckoo populations could be linked to mortality during migration, there are also many other potential factors that may operate. Host densities, synchrony between host and parasite in egg laying, breeding success in host and cuckoo and decrease in abundance of food (i.e. insects, and butterflies in particular), to mention some, may also be of importance (Mikulica et al. 2017). To disclose changes in population sizes and pinpoint the potential reasons for these changes, it is important to monitor the breeding biology of the cuckoo through long-term studies. We therefore carried out a study to investigate interactions between Meadow Pipits and cuckoos in two different mountain areas located in the eastern and western part of southern Norway. We also studied Meadow Pipits nesting in a control area at a higher level (above the tree line) where cuckoos are absent. We report parasitism rates, host rejection rates, egg characteristics, predation rates and egg-laying dates, which are all variables that may influence the state of the cuckoo population.

Increasing temperatures due to climate change are especially pronounced in the northern hemisphere, and have been linked to changes in bird populations in this area. The Meadow Pipit is a so-called short-distance migrant mostly wintering in southern or central Europe. Higher temperatures have advanced the spring migration and start of breeding of many species like the 
Meadow Pipit (Møller et al. 2010, Møller 2011).

On the other hand, the cuckoo is a long-distance migrant, wintering in tropical Africa south of the Sahara. Accordingly, cuckoos are probably not able to track the advanced spring in the breeding areas, and therefore should return to their breeding grounds at more or less the same time even with warmer springs in the breeding areas. It has therefore been hypothesized that the climate change has a greater influence on the Meadow Pipit migration than on cuckoo migration (Møller et al. 2010, Møller 2011). As a result, the Meadow Pipit may start to lay eggs earlier, and could accordingly become a less suitable host because the cuckoo would arrive too late to utilize them (Saino et al. 2009, Barrett 2014). This hypothesis has received some support from Møller et al. (2010), who found that long-distance migrants at present are relatively more used by cuckoos than short-distance migrants. The present study will provide support for the "mismatch" hypothesis if Meadow Pipit nests early in the season are parasitized less than later ones, otherwise not.

\section{MATERIALS AND METHODS}

Study areas and field work 2001-2014

Area $I$. This area is located in Øyer mountains $\left(61^{\circ} 13^{\prime}\right.$ to $61^{\circ} 16^{\prime} \mathrm{N}, 10^{\circ} 33^{\prime}$ to $10^{\circ} 42^{\prime} \mathrm{E}$ ) in the eastern part of Norway, consisting of moors, heathers, and scattered patches of small birches and some pines. The level above the sea varied from about 850 to 1000 metres. Cuckoos were regularly observed in this area (see also Berstad 2008).

Area II. This area is located in Filefjell mountains $\left(61^{\circ} 08^{\prime}\right.$ to $61^{\circ} 10^{\prime} \mathrm{N}, 08^{\circ} 00^{\prime}$ to $\left.08^{\circ} 09^{\prime} \mathrm{E}\right)$ in the western part of Norway. It is a broad mountain valley consisting of moors, heathers, and scattered patches of small mountain birches. The level above the sea varied from about 900 to 1000 metres. Cuckoos were regularly observed in this area.

Control area. This area is located in the Tyin mountains $\left(61^{\circ} 16^{\prime}\right.$ to $61^{\circ} 18^{\prime} \mathrm{N}, 08^{\circ} 14^{\prime}$ to $\left.08^{\circ} 17^{\prime} \mathrm{E}\right)$ and is situated above the tree line and close to Area II. Altitude varied from about 1100 to 1200 metres. Cuckoos were not observed in this area.

\section{Field procedures}

Search for nests in the study areas was carried out from about 12 June and to the first part of July each year. A team of nest searchers walked slowly through the areas aiming to cover as much of the area as possible. The nests were found by flushing the Meadow Pipits off their nest. The flushing distance was usually between 0.5 and 2 metres. When a nest was found, details about number of eggs or nestlings were recorded, photos were taken of the contents. All nests were controlled regularly until hatching, while parasitized nests were controlled until chicks were predated or fledged. The eggs were taken out of the nests with a plastic spoon, and then photographed on a white background (Berstad 2008). This operation was done quickly and carefully, and no Meadow Pipit nests were abandoned following the disturbance.

The day of laying the first egg, day of incubation and day of hatching were estimated based on the number of eggs in the clutch on subsequent days (egglaying) or from backward counting from hatching based on estimated age of nestlings. For estimations of first day of egg-laying we used an incubation time of 13 days for the Meadow Pipit and 12 days for the cuckoo (Wyllie 1981, Wahlberg 1993). Colour and marking characteristics of Meadow Pipit and cuckoo eggs were assessed visually at the nest and from photos.

In order to study host selection, nests of passerine birds other than Meadow Pipits found during nest search were also recorded in the same way as described above.

\section{RESULTS}

A total of 211 Meadow Pipit nests were found, with 129 nests in Area I and 82 nests in Area II, respectively (Table 1). Altogether, cuckoo parasitism was found in $6.6 \%$ of the nests $(n=211), 8.5 \%$ in Area I and $3.5 \%$ in Area II. Ten cuckoo eggs and four cuckoo nestlings were found. As shown in Table 1 the frequency of parasitism varied from year to year and for the two

Table 1. Total number of Meadow Pipit nests with a Common Cuckoo egg or chick with number of nests recorded (in brackets) in the period 2001-2014 in Area I (Øyer) and Area II (Filefjell). The Controls are nests from an area at a higher level above the sea (Tyin). Nests in period 2001-2004 are merged due to small sample sizes each year.

\begin{tabular}{llll}
\hline & & & \\
Year & Area I & Area II & Control \\
\hline $2001-2004$ & $2(14)$ & $1(18)$ & $0(5)$ \\
2005 & $6(17)$ & - & $0(1)$ \\
2006 & $0(7)$ & - & $0(6)$ \\
2007 & $1(9)$ & - & $0(10)$ \\
2008 & - & $0(22)$ & $0(1)$ \\
2009 & $1(14)$ & - & $0(1)$ \\
2010 & $1(22)$ & - & $0(1)$ \\
2011 & $0(12)$ & - & - \\
2012 & $0(2)$ & $0(16)$ & $0(2)$ \\
2013 & $0(8)$ & $2(13)$ & - \\
2014 & $0(24)$ & $0(13)$ & - \\
\hline Total & $11(129)$ & $3(82)$ & $0(27)$ \\
\hline
\end{tabular}


Table 2. Mean date for first egg laid in clutches of Meadow Pipits with number of nests recorded (in brackets) in the period 2004-2014 in Area I (Øyer) and Area II (Filefjell). Mean egg laying date for Common Cuckoos are also reported with numbers of parasitized nests (in brackets). In each row the mean laying date for Meadow Pipits and Common Cuckoos are separated by /. The row "Average» indicates the mean date for all years using the unweighted means per year (as they appear in this table without weighting differences in sample sizes between years).

\begin{tabular}{lll}
\hline Year & Area I & Area II \\
\hline 2004 & 4 June (6) / 7 June (2) & - \\
2005 & 12 June (8) / 17 June (6) & - \\
2006 & 8 June (4) / No parasitism & - \\
2007 & 2 June (7) / 24 June (1) & - \\
2008 & - & 10 June (16) / No parasitism \\
2009 & 6 June (10) / 6 June (1) & - \\
2010 & 0 June (20) / 12 June (1) & - \\
2011 & 2 June (11) / No parasitism & - \\
2012 & - & 10 June (13) / No parasitism \\
2013 & 3 June (8) / No parasitism & 6 June (11) / 10 June (1) \\
2014 & 6 June (22) / No parasitism & 8 June (9) / No parasitism \\
& 5 June (9) / 13 June (5) & 8 June (4) / 10 June (1) \\
\hline
\end{tabular}

areas studied. The highest annual parasitism was found in Area I in $2005(35.3 \%, \mathrm{n}=17)$. In the period 2006 to 2014 , however, only five nests were parasitized in the two areas combined. The total number of Meadow Pipit eggs could be counted in 186 unparasitized nests, giving a mean clutch size of 5.0 eggs. In eight nests with a cuckoo egg, the average number of host eggs was 3.5 , resulting in a shortage of 1.5 eggs compared to unparasitized nests.

In 10 parasitized nests found with eggs, we did not observe ejection of the cuckoo egg. In three parasitized nests containing cuckoo eggs $(30 \%)$, the Meadow Pipits deserted their nest. According to evaluations of the embryos in the eggs, the desertion occurred early in the incubation period. In the unparasitized nests no cases of desertion were observed, and none of the four cuckoo nestlings were deserted.

The number of nests where Meadow Pipit eggs were hatching, was regularly high in both Area I and Area II with a mean of $89.1 \%$ for the total material in years with more than 10 nests found $(\mathrm{n}=137,2008$ 2014). Predation in nests with eggs ranged $0-27.3 \%$, but there were no significant differences between years $(\chi 2=11.17$, df $=6, p=0.08)$. Predation of non-parasitized nests at the nestling stage cannot be calculated since they were not checked regularly at this stage. Out of 11 parasitized nests with cuckoo eggs or chicks (excluding the three nests where the cuckoo egg was deserted by the host), only one nest with a cuckoo chick was predated (Area I in 2005).

Figure 1 shows examples of Meadow Pipit egg clutches. The colour and markings of Meadow Pipit
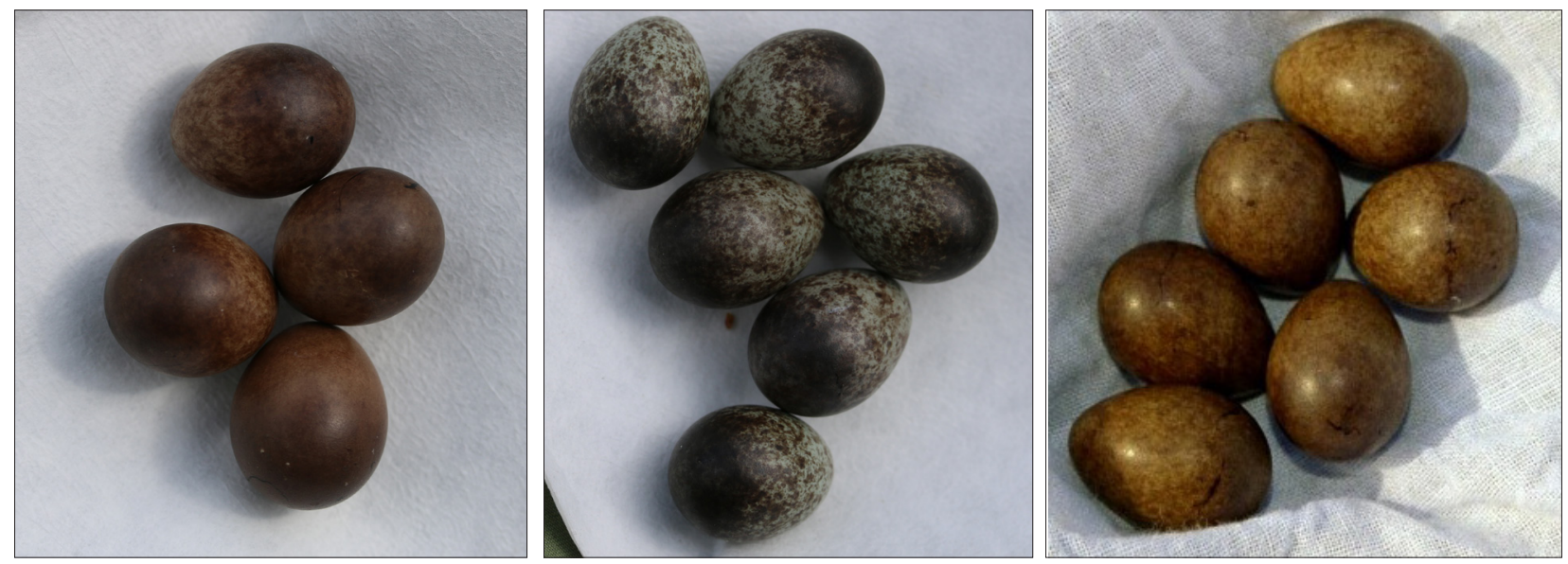

Figure 1. Examples of Meadow Pipit Anthus pratensis egg clutches showing considerable differences between but minor differences within clutches. 
a)
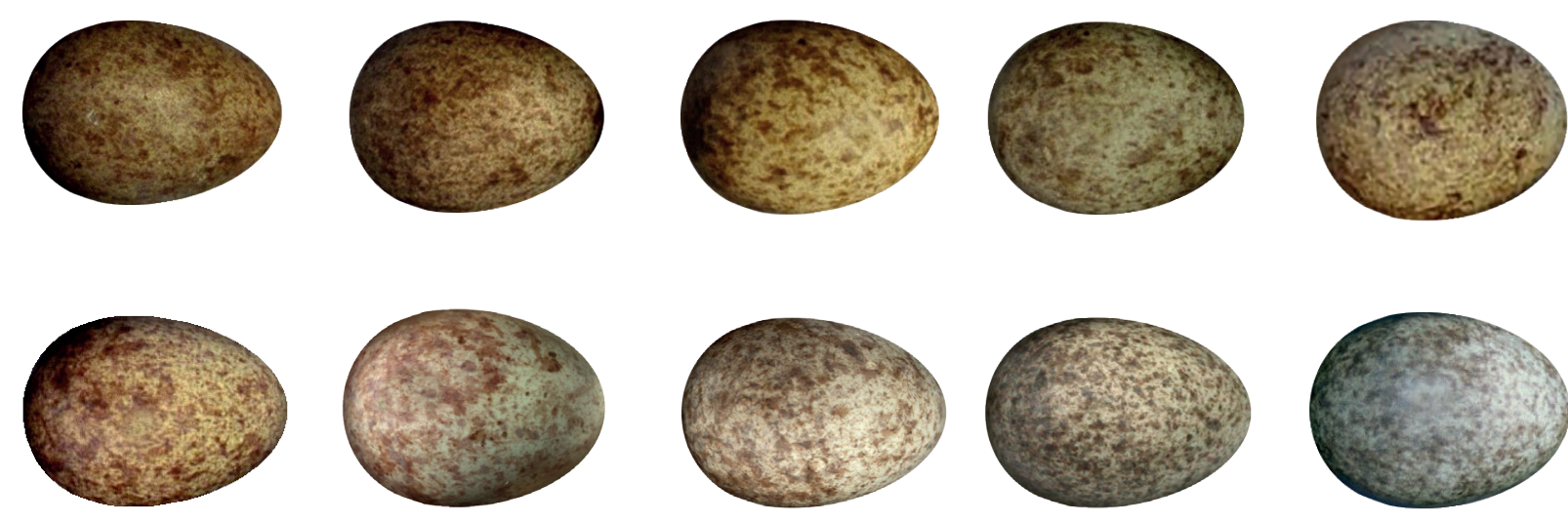

b)
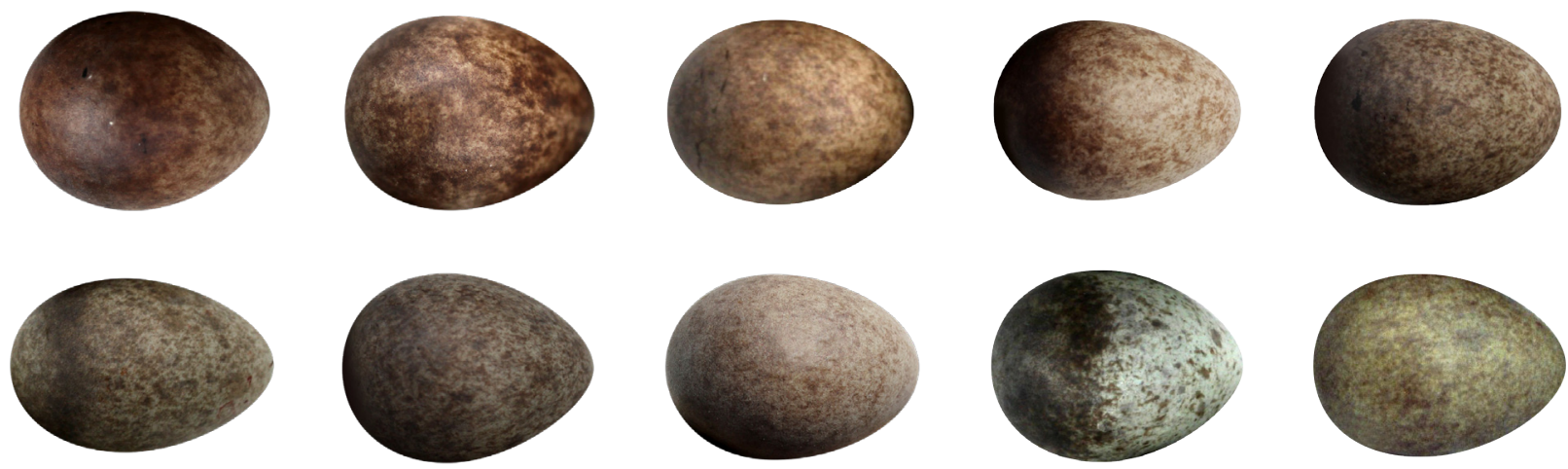

Figure 2. Eggs of Common Cuckoo Cuculus canorus (a) and Meadow Pipit Anthus pratensis (b).

eggs vary between the clutches, whereas the differences between the eggs in the same clutch regularly showed only minor differences. Photos of all the cuckoo eggs recorded and a sample of Meadow Pipit eggs are presented in Figure 2a and Figure 2b, respectively. The overall impression is that the eggs show quite good accordance between cuckoo and Meadow Pipit eggs (see Figure 3 for an example). To the human eye, the cuckoo eggs that were deserted $(n=3)$ did not appear to show poorer mimicry than those that were accepted.

The average dates for Meadow Pipits to initiate egg-laying in the period 2004-2014 are provided in Table 2. In the present material, cuckoos laid eggs from 6 to 24 June. In Area I, and for the whole data set, the average egg-laying date of the cuckoo was 14 June (n =11). In Area II, the cuckoo laid her egg on 10 and 11

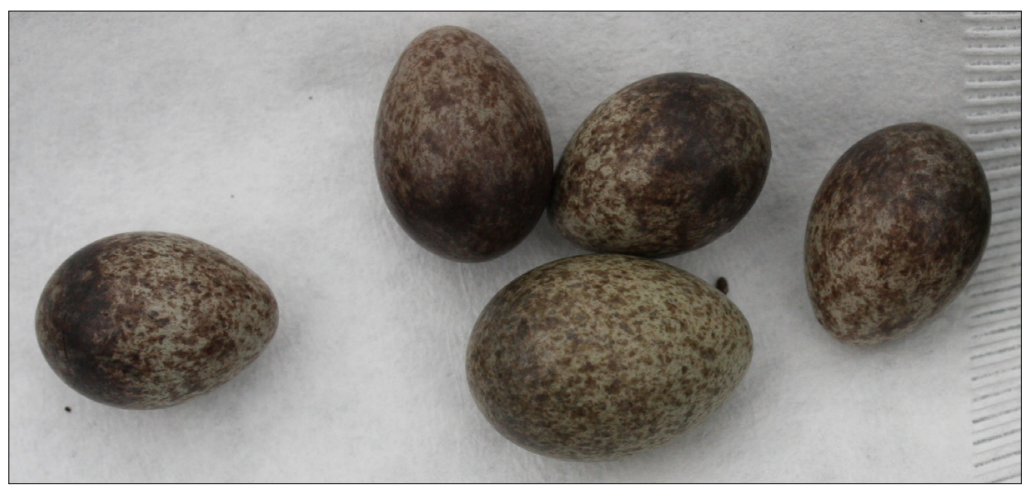

Figure 3. A clutch of Meadow Pipit Anthus pratensis eggs and a Common Cuckoo Cuculus canorus egg. The cuckoo egg shows quite good mimicry with the Meadow Pipit eggs. 


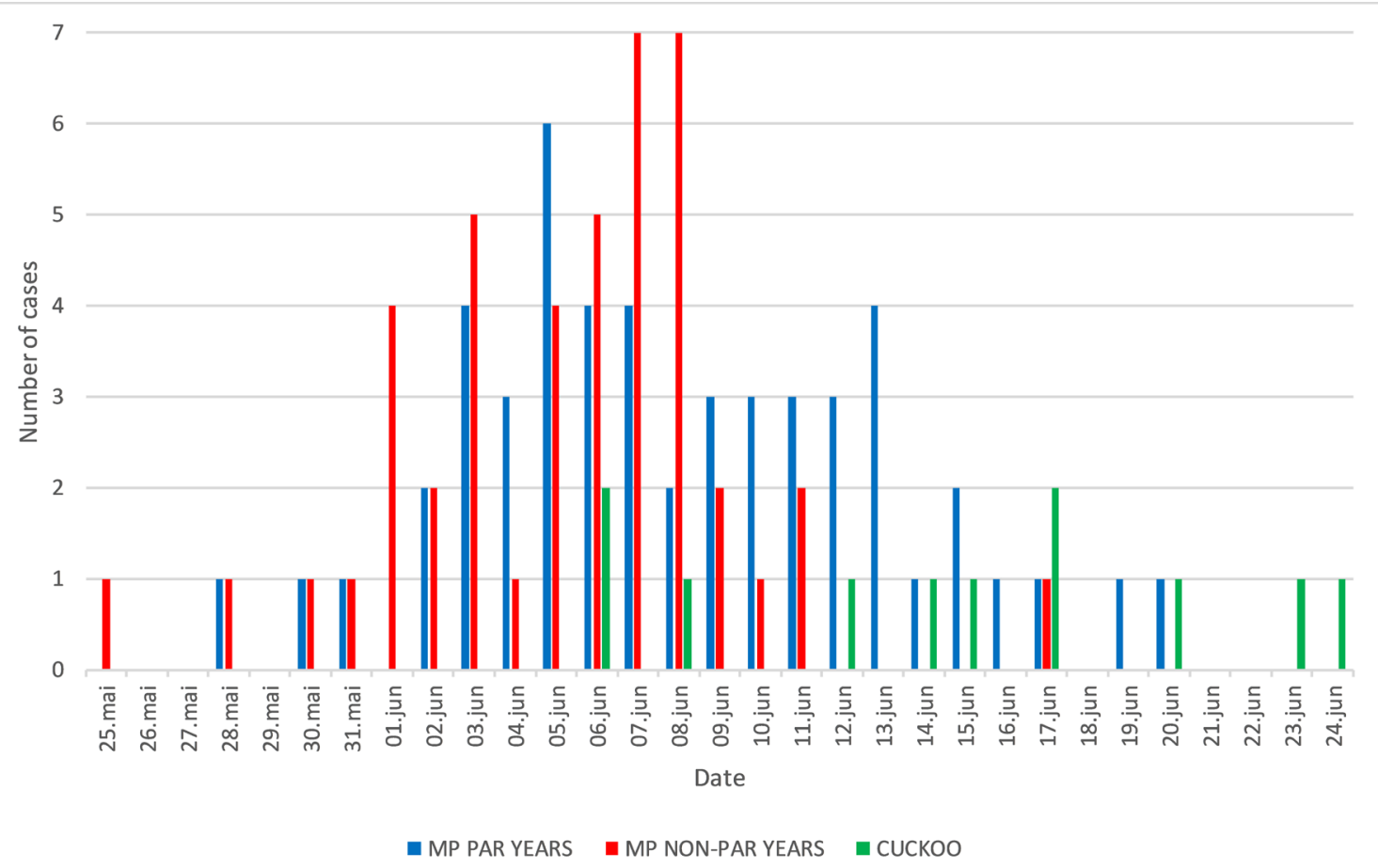

Figure 4. Dates when Meadow Pipits Anthus pratensis $(\mathrm{n}=96)$ and Common Cuckoo Cuculus canorus $(\mathrm{n}=11)$ started egg-laying in Area I (Øyer). MP PAR YEARS = Meadow Pipit laying dates in years with recorded cuckoo parasitism $(\mathrm{n}=51)$, MP NON-PAR YEARS $=$ Meadow Pipit laying dates in years without recorded cuckoo parasitism $(n=45)$, CUCKOO $=$ Common Cuckoo laying dates.

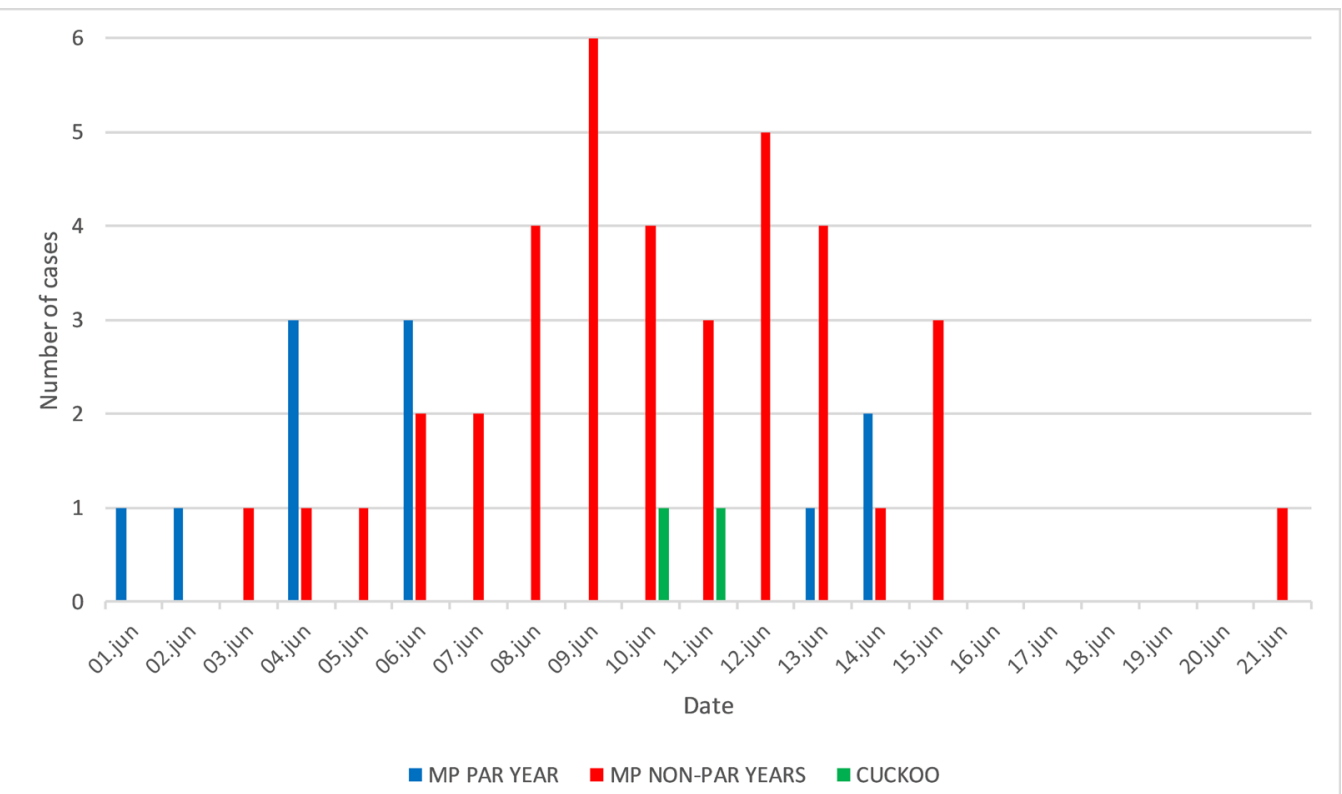

Figure 5. Dates when Meadow Pipits Anthus pratensis $(\mathrm{n}=49)$ and Common Cuckoo Cuculus canorus $(\mathrm{n}=2)$ started egg-laying in Area II (Filefjell). MP PAR YEAR = Meadow Pipit laying dates in year (2013) with recorded cuckoo parasitism $(\mathrm{n}=11)$, MP NON-PAR YEARS = Meadow Pipit laying dates in years without recorded cuckoo parasitism $(\mathrm{n}=38)$, CUCKOO = Common Cuckoo laying dates.

June $(n=2)$. In 12 of the parasitized nests both the date when the cuckoo egg was laid and the date when the Meadow Pipit started to incubate, could be estimated. In eight nests these two events were estimated to happen on the same day, and in four nests the cuckoo egg was estimated to be laid the day before the start of incubation.
The estimated dates for Meadow Pipits and cuckoos to commence egg-laying in Area I and Area II are presented in Figures 4 and 5. In Area I, mean date for first egg laid in years with confirmed parasitism (8 June $[\mathrm{SD}=5$ days], $\mathrm{n}=51$ ) was later than in years without confirmed parasitism (5 June [SD $=4$ days], $n$ $=45)$. The difference was statistically significant $(\mathrm{F}=$ 
9.07, $\mathrm{df}=1,94, \mathrm{p}=0.003$, Figure 4, Table 2). Hence, in years with parasitism, the cuckoo is reasonably able to track the egg-laying period of the host even though a proportion of the host nests are apparently laid too early for the cuckoo to utilize them. In years without parasitism, however, and based on cuckoo egglaying dates in years with parasitism, it seems that the Meadow Pipit overall lay too early for the cuckoo to optimally utilize them as hosts. In Area II, the sample sizes are too low to run any statistical tests, but it seems that cuckoos are in better synchrony with their hosts regarding egg-laying in all years (Figure 5, Table 2).

In the Control area, 27 Meadow Pipit nests were found (Table 1). In this area the average date for laying of the first egg in eight nests was 17 June. The eggs in another 19 nests in this area were not hatched before at least after 1 July, and the start of egg-laying in these nests could not be precisely estimated, but they must have been laid late in June.

No cuckoo parasitism was found in a total of 164 nests of other passerines. These were 71 nests of Willow Warbler Phylloscopus trochilus, 43 nests of Reed Bunting Emberiza schoeniclus, 31 nests of Yellow Wagtail Motacilla flava thunbergi and 19 nests of Bluethroat Luscinia svecica.

\section{DISCUSSION}

It has previously been observed that the cuckoo lays an egg every second day (Chance 1922, 1940). There have been many speculations about how many eggs the cuckoo lays in each season, and Chance (1940) observed that a female laid more than 20 eggs. In Scandinavia it has been suggested that a cuckoo may lay about eight eggs in a season (Dybro 1977, Ericson \& Sjögren 2004). In the present work we observed that the cuckoo laid eggs in a period of 18 days in June. Accordingly, it might be suggested from the present study that the total amount of eggs that may be laid by a cuckoo parasitizing Meadow Pipit nests during a season, is limited to about nine eggs. Moksnes et al. (1993) have reached similar conclusions when cuckoo parasitism of Meadow Pipits was studied in a mountain area in Central Norway.

The high rate of hatching success in Meadow Pipit nests found in the present study, may be an important factor contributing to the Meadow Pipit's role as an important cuckoo host. A similar conclusion was reached by Moksnes \& Røskaft (1987).

When laying its egg the cuckoo usually removes one or more of the host's eggs (Moksnes et al. 2011). In the present study, unparasitized Meadow Pipit nests contained 1.5 more host eggs than parasitized ones, indicating that this amount was removed by the cuckoo. This is also in close accordance with results from a study of cuckoo parasitism on Meadow Pipits in
Central Norway (Moksnes \& Røskaft 1987).

\section{Parasitism rate}

Cuckoo parasitism rate is highly variable between various host species (e.g. Moksnes \& Røskaft 1995, Rutila et al. 2002, Kleven et al. 2004) depending on many ecological and evolutionary factors (Rothstein \& Robinson 1998, Soler 2018), and also on the temporal and geographical scale. Rarely used hosts may experience parasitism rates close to zero while in frequently used hosts like Acrocephalus warblers, cuckoo eggs may be found in more than $40 \%$ of nests (Moskát \& Honza 2002, Kleven et al. 2004). The highest known parasitism rate, about $80 \%$, has been recorded in Azure-winged Magpies Cyanopica cyana in Japan (Nakamura 1990, Nakamura et al. 1998).

A mean cuckoo parasitism rate of $6.6 \%(n=211)$ in Meadow Pipits was found in the present study. This seems to be in a relatively good accordance with earlier studies. In a mountain area in Central Norway, Moksnes et al. (1993) found a parasitism rate of 5.1 $\%(\mathrm{n}=454)$, and Lack (1963) reported a parasitism rate of $9 \%(n=77)$ in Meadow Pipits in north-eastern England. Glue \& Murray (1984), however, reported a rate of $3 \%(n=5331)$ on a national scale in England. Our study too shows that both the spatial and temporal scale is important for estimations of parasitism rates, since it varied significantly both between years and areas.

It is difficult to conclude about the reason for the marked decline in parasitism rate from the period 2004-2005 to the period 2006-2014. One potential explanation is obviously the general decrease in the Norwegian cuckoo population (Moksnes 2014), but at least in Area I, it could also partly be due to a possible mismatch between the cuckoo and Meadow Pipit egg-laying periods (see below). Another possible and not mutually exclusive explanation is increasing difficulties for cuckoos to find an adequate number of host nests to utilize. In the period 1996-2014 it has been shown that Meadow Pipit numbers have declined in Scandinavia, including Norway (Kålås et al. 2014, Lehikoinen et al. 2019). Difficulty in finding host nests may lead to lower reproductive output for the cuckoo, resulting in reduction or loss of local populations.

In this study no cuckoo parasitism was found in nests of the Bluethroat, Reed Bunting, Yellow Wagtail and Willow Warbler. These results confirm the Meadow Pipit's position as the dominating main host for the cuckoo in mountain areas in Norway.

\section{Rejection rate and egg mimicry}

In the present study, $30 \%$ of Meadow Pipit nests with 
a cuckoo egg were deserted. In general, there may be several reasons for abandoning nests (e.g. bad weather or disturbance), but for Meadow Pipits it is convincingly shown that desertion is a real defence response against cuckoo parasitism (Davies \& Brooke 1989, Moksnes et al. 1991). Even if a few nests may be deserted for other reasons, the observed rejection rate can probably be regarded as an underestimate because it is very difficult to find nests already deserted. Accordingly, the parasitism rate found in the present study is probably underestimated too. However, since egg mimicry in general was regarded as rather good in the study areas, the observed parasitism rate probably does not deviate very much from the actual one.

The estimated rejection rate reported in this study is based on few data and must therefore be handled with care. In spite of this it is interesting to note that the rejection rate is in accordance with experimental results from Great Britain (Davies \& Brooke 1989). When mimetic model cuckoo eggs were introduced in nests of British Meadow Pipits, 22.2\% $(n=27)$ of the birds deserted. When such experiments were carried out in mountain areas in Central Norway (Moksnes et al. 1993), however, the desertion rate of mimetic model eggs was only $4.8 \%$ and not significantly different from the control group (no parasitism). Moksnes et al. (1993) have discussed the possible reasons for different rejection rates between populations. There may be several reasons for such variations; e.g. different length of breeding season or different possibility for the cuckoo to operate in secret; experiments show that parasitized Meadow Pipits will be considerably more prone to reject the parasitic egg if they in addition observe a cuckoo at their nest (Moksnes et al. 1993).

\section{Mismatch due to climate change?}

The results did show that there is a considerable annual variation in the commencement of the Meadow Pipit egg-laying period, and that in some years the cuckoo may be out of synchrony with the host. This was especially prominent in one of the study areas (Area I). Accordingly, the present work provides some support for the assumption that climate changes possibly might cause a mismatch between the cuckoo and the Meadow Pipit breeding season (Saino at al. 2009, Møller et al. 2010). However, we have to point out that the number of cases of parasitism in the present study was rather low, making it difficult to make thorough interpretations.

A convincing support for the importance of local climate conditions for the time when Meadow Pipit started nesting was the marked influence of the level above the sea. A nesting delay of at least 8 days was observed in the control area located close to Area II, at a level of 1100 to 1200 metres above the sea compared to 900 to 1000 metres above the sea for Area II. In such areas it would therefore possibly be more optimal for cuckoos to utilize Meadow Pipits in the future, but the lack of proper vantage points for nest searching may prove to be an obstacle for the cuckoos (e.g. Røskaft et al. 2002). In addition, currently, high altitude areas may also prove to be suboptimal to adult cuckoos since they may contain few adequate feeding sites for cuckoos. Adult cuckoos mainly feed on caterpillars (Mikulica et al. 2017), which may be difficult to find in such areas.

Acknowledgements. We want to thank our co-workers in the field: Bjørn Bjørlykke, Magne Garlid, Jess HolmboeErichsen, Anders Lundberg, Atle Myklebust, Inge Selås, Øyvind Traagstad and Bjørn Tvedt. We also express our thanks to two anonymous referees for constructive comments that significantly improved the quality of the manuscript.

\section{REFERENCES}

Barrett, R.T. 2014. Has climate change resulted in a mismatch between the spring arrival of the Common Cuckoo Cuculus canorus and its hosts in North Norway. Ornis Norvegica 37: 11-14.

Berstad, J. 2008. Common Cuckoo Cuculus canorus parasitizing nests of Meadow Pipit Anthus pratensis. Some findings from a mountainous area in Norway. Ornis Norvegica 31: 98-104. (In Norwegian with English summary).

Birdlife International 2004. Birds in Europe: population estimates, trends and conservation status. Birdlife International, Cambridge.

Chance, E. 1922. The Cuckoo's Secret. Sidgwick \& Jackson Ltd., London.

Chance, E.P. 1940. The truth about the Cuckoo. Country Life Ltd., London.

Davies, N.B. \& Brooke, M. de L. 1989. An experimental study of co-evolution between the Cuckoo Cuculus canorus, and its hosts. I. Host egg discrimination. J. Anim. Ecol. 58: 207-224.

Dybro, T. 1977. Gøgen. Naturens Verdens Dyrebibliotek. Rhodos, Copenhagen. (In Danish).

Eaton, M.A., Brown, A.F., Noble, D.G., Musgrove, A.J., Hearn, R., Aebischer, N.J., Gibbons, D.W., Evans, A. \& Gregory, R.D. 2009. Birds of conservation concern 3: the population status of birds in the United Kingdom, Channel Islands and the Isle of Man. Br. Birds 102: 296-341.

Ericson, P.G.P. \& H. Sjögren 2004. Boken om göken. Atlantis Stockholm. (In Swedish).

Erritzøe, J., Mann, C.F., Brammer, F.P. \& Fuller, R.A. 2012. Cuckoos of the world. Christoffer Helm, London,

Glue, D. \& Murray, E. 1984. Cuckoo hosts in Britain. BTO News 134: 5.

Hewson, C.M., Thorup, K., Pearce-Higgins, J.W. \& Atkinson, P.W. 2016. Population decline is linked to migration route in the Common Cuckoo. Nature Comm.7: Article no. 12296. 
Kleven, O., Moksnes, A. Røskaft, E., Rudolfsen, G., Stokke, B.G. \& Honza, M. 2004. Breeding success of Common Cuckoos Cuculus canorus parasitising four sympatric species of Acrocephalus warblers. J. Avian Biol. 35: 394-398.

Kålås, J.A., Husby, M., Vang, R. \& Nilsen, E.B. 2014. Terrestriske fugler i Norge - bestandsendringer 19962013. Vår Fuglefauna 37: 14-20. (in Norwegian).

Lack, D. 1963. Cuckoo hosts in England. Bird Study 10: 185-203.

Lehikoinen, A., Brotons, L., Calladine, J., Campedelli, T., Escandell, V., Flousek, J., Grueneberg, C., Haas, F., Harris, S., Herrando, S., Husby, M., Jiguet, F., Kålås, J.A., Lindström, Å., Lorrillière, R., Molina, B., Pladevall, C., Calvi, G., Sattler, T., Schmid, H., Sirkiä, P.M., Teufelbauer, N. \& Trautmann, S. 2019. Declining population trends of European mountain birds. Global Change Biol. 25: 577-588.

Mikulica, O., Grim, T., Schulze-Hagen, K. \& Stokke, B.G. 2017. The Cuckoo. The uninvited guest. Wild Nature Press, Plymouth.

Moksnes, A. \& Røskaft E. 1987. Cuckoo host interactions in Norwegian mountain areas. Ornis Scandinavica 18: $168-172$.

Moksnes, A. \& Røskaft, E. 1995. Egg-morphs and host preference in the Common Cuckoo (Cuculus canorus): an analysis of Cuckoo and host eggs from European museum collections. J. Zool., Lond. 236: 625-648.

Moksnes, A., Røskaft, E. \& Braa, A.T. 1991. Rejection behavior by Common Cuckoo hosts towards artificial brood parasite eggs. Auk 108: 348-354.

Moksnes, A., Røskaft, E. \& Korsnes, L. 1993. Rejection of Cuckoo (Cuculus canorus) eggs by Meadow Pipits (Anthus pratensis). Behav. Ecol. 4: 120-127.

Moksnes, A., Røskaft E. \& Stokke, B.G. 2011. Gjøkens forunderlige verden. Tapir Akademisk Forlag, Trondheim. (In Norwegian).

Moksnes, A. 2014. Hvor blir det av gjøken? Vår Fuglefauna 37: 22-23. (In Norwegian).

Møller, A.P., Saino, N., Adamik, P., Ambrosini, R., Antonov, A., Campobello, D., Stokke, B.G., Fossøy, F., Lehikoinen, E., Martin-Vivaldi, M., Moksnes, A., Moskat, C., Røskaft, E., Rubolini, D., Schulze-Hagen, K., Soler, M. \& Shykoff, J.A. 2010. Rapid change in host use of the Common Cuckoo Cuculus canorus linked to climate change. Proc. R. Soc. B. 278: 733-738.
Møller, A.P. 2011. Climate change and birds. Pp. 13-39 in: del Hoyo, J., Elliott, A. \& Christie, D. (Eds.). Handbook of the birds of the world. Vol. 16. Tanagers to New World blackbirds. Lynx Editions, Barcelona.

Moskát, C. \& Honza, M. 2002. European Cuckoo Cuculus canorus parasitism and host's rejection behaviour in a heavily parasitized Great Reed Warbler Acrocephalus arundinaceus population. Ibis 144: 614-622.

Nakamura, H. 1990. Brood parasitism by the Cuckoo Cuculus canorus in Japan and the start of new parasitism on the Azure-winged Magpie Cyanopica cyana. Jap. J. Ornith. 39: 1-18.

Nakamura, H., Kubota, S. \& Suzuki, R. 1998. Coevolution between the Common Cuckoo and its major hosts in Japan. Pp. 94-112 in: Rothstein S.I. \& Robinson, S.K. (Eds.). Parasitic birds and their hosts. Oxford University Press, Oxford.

Rothstein, S.I. \& Robinson, S.K. 1998. Parasitic birds and their hosts. Oxford University Press, New York, Oxford.

Rutila, J., Latja R. \& Koskela K. 2002. The Common Cuckoo Cuculus canorus and its cavity nesting host, the Redstart Phoenicurus phoenicurus: a peculiar cuckoohost system? J. Avian Biol. 33: 414-419.

Røskaft, E., Moksnes, A., Stokke, B.G., Moskát, C. \& Honza, M. 2002. The spatial habitat structure of host populations explains the pattern of rejection behavior in hosts and parasitic adaptations in cuckoos. Behav. Ecol. 13: $163-168$.

Saino, N., Rubolini, D., Lehikoinen, E., Sokolov, R.V., Bonisoli-Alquati, A., Ambrosini, R., Boncoraglio, G. \& Møller, A.P. 2009. Climate change effects on migration phenology may mismatch brood parasitic cuckoos and their hosts. Biol. Letters 5: 539-541.

Soler, M. (Ed.) 2018. Avian brood parasitism. Behaviour, ecology, evolution and coevolution. Springer International Publishing, Berlin.

Wahlberg, T. 1993. Kunnskapen om fåglar. Alla häckande arter i Sverige. Bokførlaget EKO, Uppsala, Sverige. (In Swedish).

Wyllie, I. 1981. The Cuckoo. Batsford, London.

Received 22 January 2019. Accepted 10 April 2019 